\title{
Motivações da docência em matemática: discurso de professores da rede pública de ensino ${ }^{1}$
}

\author{
Motivaciones de la docencia en matemáticas: discurso de profesores de la \\ red pública de enseñanza
}

\author{
Motivations of teaching in mathematics: discourse of teachers of the public \\ school system
}

Luana Maria Santos da Silva Ayres ${ }^{2}$

Tanise Paula Novello ${ }^{3}$

\begin{abstract}
Resumo
A satisfação profissional é um dos fatores que mais influência no bem-estar das pessoas. No trabalho docente não é diferente, ou seja, o professor que está satisfeito com sua escolha e prática profissional tem mais chances de desenvolver bem-estar, que é evidenciado na docência pela dedicação, contentamento e felicidade que o professor expressa no exercício da docência. Nesse contexto, este estudo tem como objetivo investigar as motivações dos professores em relação à docência em matemática. A produção de dados aconteceu por meio de um questionário online, com 94 professores de matemática de escolas públicas. O questionário foi organizado em três eixos: variáveis sociodemográfica e laborais; dez questões fechadas; e uma questão aberta: "O que você diria a um jovem que está fazendo a escolha pela licenciatura em matemática? Registre teus sentimentos e percepções a partir do que tens vivenciado na tua prática". Porém, nesse trabalho será contemplado somente 30 relatos da questão aberta, que, através do Discurso do Sujeito Coletivo (DSC), definiu um discurso intitulado "Motivações dos Professores" que versa sobre as motivações que os professores sentem em relação a prática docente. Pela análise do DSC constatou-se que os professores, embora exista uma desvalorização da profissão, conseguem sentir prazer em lecionar, percebem que são importantes no processo de formação dos estudantes, e conseguem, através de metodologias diferenciadas, mostrar o encanto da matemática para os discentes. Com os resultados deste trabalho, acredita-se que os sentimentos positivos em relação a profissão não apenas são importantes para a saúde do professor, mas refletem também no seu desempenho em sala de aula.
\end{abstract}

Palavras-chaves: Escolha profissional; Motivação; Professores de matemática.

\section{Resumen}

La satisfacción profesional es uno de los factores que más influyen en el bienestar de las personas. En el trabajo docente no es diferente, es decir, el profesor que está satisfecho con su elección y práctica profesional tiene más posibilidades de desarrollar bienestar, que es evidenciado en la docencia por la dedicación, contentamiento y felicidad que el profesor expresa en el ejercicio de la docencia. En este contexto, este estudio tiene como objetivo investigar las motivaciones de los profesores en relación a la docencia en matemáticas. La producción de datos se produjo a través de un cuestionario en línea, con 94 profesores de matemáticas de escuelas públicas. El cuestionario se organizó en tres ejes: variables sociodemográficas y laborales; diez cuestiones cerradas; y una pregunta abierta: "Qué dirías a un joven que está haciendo la elección por la licenciatura en matemáticas? Registre tus sentimientos y percepciones a partir de lo que has vivido en tu práctica." Sin embargo, en este trabajo se contemplarán sólo 30 relatos de la cuestión abierta, que, a través del Discurso del Sujeto Colectivo (DSC), definió un discurso titulado "Motivaciones de los Profesores" que versa sobre las motivaciones que los

\footnotetext{
${ }^{1}$ Essa pesquisa tem financiamento da CAPES.

${ }^{2}$ Mestranda do Programa de Pós-graduação em Educação em Ciência, Universidade Federal do Rio Grande FURG, Rio Grande, Rio Grande do Sul, Brasil, luana_ayres@furg.br

${ }^{3}$ Doutora em Educação Ambiental, Universidade Federal do Rio Grande - FURG, Rio Grande, Rio Grande do Sul, Brasil, tanisenovello@furg.br
} 
profesores sienten en relación a la práctica docente. Por el análisis del DSC se constató que los profesores, aunque exista una desvalorización de la profesión, logran sentir placer en enseñar, perciben que son importantes en el proceso de formación de los estudiantes, y logran, a través de metodologías diferenciadas, mostrar el encanto de las matemáticas para los estudiantes. Con los resultados de este trabajo, se cree que los sentimientos positivos en relación a la profesión no sólo son importantes para la salud del profesor, sino que reflejan también en su desempeño en el aula.

Palabras claves: Elección profesional; Motivación; Profesores de matemáticas.

\begin{abstract}
Job satisfaction is one of the factors that most influence people's well-being. In the teaching work is no different, that is, the teacher who is satisfied with his choice and professional practice is more likely to develop well-being, which is evidenced in teaching by the dedication, contentment and happiness that the teacher expresses in the exercise of teaching. In this context, this study aims to investigate the motivations of teachers in relation to teaching in mathematics. The data production took place through an online questionnaire, with 94 teachers of public school mathematics. The questionnaire was organized in three axes: sociodemographic and labor variables; ten closed questions; and an open question: "What would you say to a young who is making the choice for a degree in mathematics? Record your feelings and perceptions from what you have experienced in your practice." However, in this work will be contemplated only 30 reports of the open question, which, through the Discourse of the Collective Subject (DSC), defined a discourse entitled "Motivations of Teachers" that deals with the motivations that teachers feel in relation to teaching practice. The analysis of the DSC showed that teachers, although there is a devaluation of the profession, can feel they are happy to be teaching, they perceive that they are important in the process of training students, and they can, through different methodologies, show the charm of mathematics for the students. With the results of this work, we believe that positive feelings about the profession are not only important for the health of the teacher, but also reflect on their performance in the classroom
\end{abstract}

Keywords: Professional choice; Motivation; Mathematics teachers.

\title{
1. Contextualização do estudo
}

A docência tem um papel importante na sociedade, pois o professor é responsável por realizar o processo de mediação na construção de conhecimento dos alunos, e ainda, através da sua ação, os alunos podem desenvolver, dentre outras habilidades e competências, consciência crítica. Porém, no contexto de alguns cursos de Licenciatura em Matemática, os licenciandos têm sua formação inicial voltada, na maior parte, para disciplinas específicas da Matemática, como cálculos e álgebras, e não para a formação de professores, desta forma quando o educando adentra as escolas, percebe que, em parte, a formação inicial, muitas vezes, não dá conta da realidade encontrada nas escolas.

De acordo com Tardif (2002, p. 11), a entrada na carreira docente "[...] é um período realmente importante na história profissional do professor, determinando inclusive seu futuro e sua relação com o trabalho". Mello (2000, p. 103) salienta que a educação inicial do professor torna-se "uma experiência isomorfa à experiência de aprendizagem que ele deve facilitar a seus futuros alunos, ou seja, um aprender que permite apropriar-se de estruturas comuns abstraindo as diferenças de conjuntura". Porém, alguns docentes, não tiveram sua formação inicial voltada para a realidade das escolas, desta forma o professor, tende a ter 
dificuldades de se adaptar, uma vez que, ele foi instruído a preparar suas aulas com diferenciais, através de recursos tecnológicos, materiais manipuláveis ou dinâmicas para envolver os alunos e, ao chegar na escola, se depara muitas vezes coma falta de suporte para a realização de tais aulas, e isso causa desmotivação e sentimento de impotência nesse professor.

Somado a esse fator, o professor ainda sofre com a desvalorização tanto salarial, quanto social. Com isso, à docência vai perdendo o seu encanto e a desmotivação vai crescendo nos professores conforme vai aumentando o tempo que lecionam nas escolas, como consequência, o cenário educacional perde o encanto, tanto para o professor, quanto para o aluno e isso reflete fortemente no futuro da carreira docente no país. Em concordância Souto (2013, p. 4560) afirma que a docência é vista como uma profissão menor, “[...] os salários pouco atraentes e a falta de horizontes promissores na carreira docente interferem na representação social da profissão e, consequentemente, nas escolhas profissionais dos jovens pela profissão de professor.

De acordo com Lipp (2012, p. 66), muitos professores “deixam a profissão porque não conseguem lidar com os fatores estressantes; outros permanecem, mas parecem contar os dias que faltam para os fins de semana, para as férias e, finalmente, para a aposentadoria". Com professores doentes e insatisfeitos é provável que a qualidade da educação não melhore, pois, possivelmente, estarão na sala de aula insatisfeitos e desmotivados.

Mas, salienta-se que mesmo diante da baixa procura pela profissão docente, muitos que fazem essa opção estão satisfeitos com sua escolha e a satisfação profissional é observada no trabalho desempenhado. Fato que gera o bem-estar psicológico e melhora o desempenho nas atividades docentes (CARDOSO; COSTA, 2016). Este dado é relevante, pois, de acordo com Barreiros (2008, p.10), "para que haja uma educação de qualidade, é preciso que os professores estejam capacitados a lecionar, que se dediquem e que tenham competência".

Desta forma, professores satisfeitos e motivados tendem a se dedicar mais e a desempenharem sua função com maior qualidade, pois possuem sentimentos prazerosos em relação ao oficio da docência. Nesse sentido, essa pesquisa tem o objetivo investigar as motivações dos professores em relação à docência em matemática.

Na próxima seção será evidenciado o método de produção dos registros, bem como o detalhamento dos 94 professores formados em matemática que participaram da pesquisa, assim como do instrumento proposto.

\section{Método de produção de registros na pesquisa}


Para a produção dos dados desta pesquisa disponibilizou-se um questionário através de uma plataforma digital online, Google forms. Esse questionário foi respondido por 94 professores de matemática de instituições públicas de ensino básico. O convite para responder o questionário foi enviado por meio de emails em novembro de 2017, o contato dos professores foi obtido através da lista de participantes do Encontro Brasileiro de Estudantes de Pós-Graduação em Educação Matemática (EBRAPEM), que ocorreu no início de novembro de 2017 na Universidade Federal de Pelotas (UFPel) - Pelotas/RS.

O questionário foi organizado em três eixos: o primeiro relativo a variáveis sociodemográficas (sexo, idade e estado civil) e laborais (titulação mais elevada, tempo de docência e carga horária); o segundo composto de 10 questões fechadas sobre os sentimentos na docência; e o terceiro compreendido por uma questão aberta que perguntava aos professores, com bases nas experiências, o que eles poderiam dizer aos jovens que estão optando pelo curso de Licenciatura em Matemática. Salienta-se que nessa escrita será abordado apenas o primeiro eixo e 30 relatos da questão aberta, que pertencem ao terceiro eixo, desse questionário.

O primeiro eixo do questionário, foi analisado utilizando como técnica a Estatística Descritiva e através dessa análise foi possível traçar o perfil dos professores que participaram da pesquisa. Em relação as variáveis sociodemográficas, observou-se que $69 \%$ dos professores são do gênero feminino e $31 \%$ masculino. A idade varia entre 23 anos e 65 anos, sendo que a média foi de aproximadamente 36 anos. Em relação ao estado civil 52,1\% são casados; $23,4 \%$ são solteiros; $13,8 \%$ têm união estável; $8,5 \%$ são divorciados; e 2,1\% são separados. Conforme pode-se observar na Figura 1, 21\% dos participantes possuem somente graduação; $41 \%$ possuem alguma especialização; $34 \%$ possuem mestrado; e 4\% possuem doutorado. 


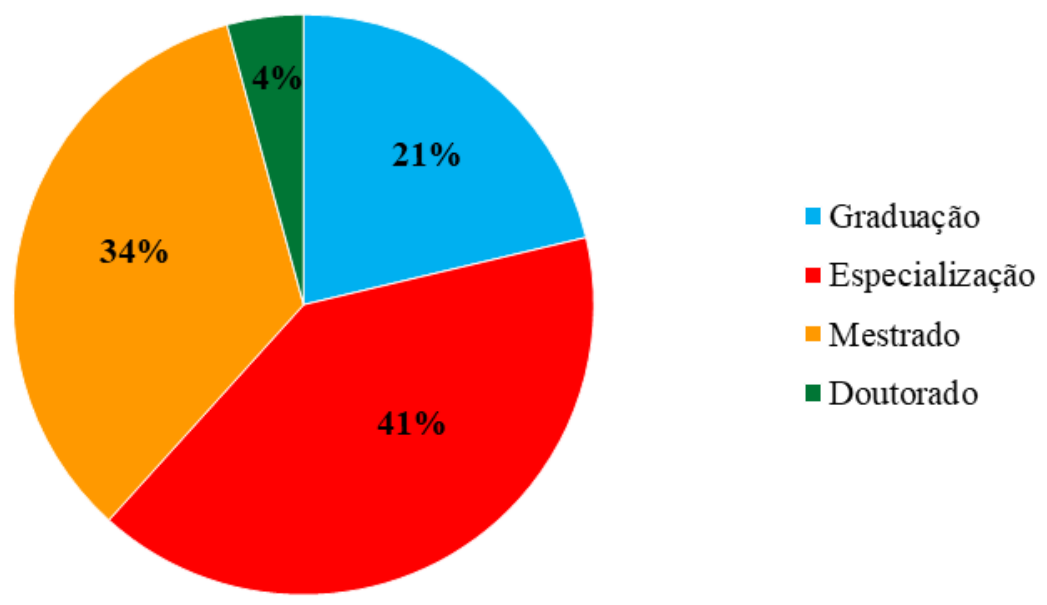

Figura 1 - Formação Acadêmica dos Professores.

Fonte: Os autores.

Em relação as variáveis laborais, os professores trabalham aproximadamente 30 horas por semana, e o tempo que atuam na docência é, em média, 10 anos. Como é possível verificar (Figura 2), 46\% dos professores lecionam apenas para o Ensino Fundamental; 14\% somente para o Ensino Médio; e 40\% lecionam tanto para o Ensino Fundamental como para o Ensino Médio.

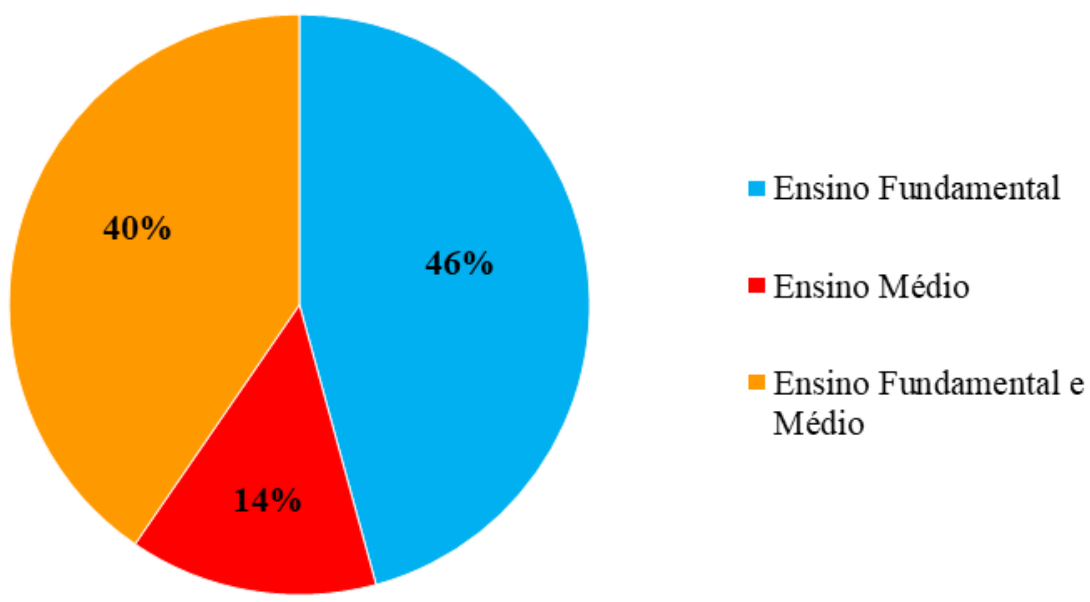

Figura 2 - Nível de atuação escolar dos docentes.

Fonte: Os autores.

O terceiro eixo do questionário foi composto da seguinte questão: "O que você diria a um jovem que está fazendo a escolha pela licenciatura em matemática? Registre teus 
sentimentos e percepções a partir do que tens vivenciado na tua prática”, que foi analisada através do Discurso do Sujeito Coletivo (DSC). De acordo com Duarte, Mamede e Andrade (2009, p. 623) "o DSC é uma técnica de construção do pensamento coletivo que visa revelar como as pessoas pensam, atribuem sentidos e manifestam posicionamentos sobre determinado assunto. Trata-se de um compartilhamento de ideias dentro de um grupo social.

O DSC é composto de três figuras de linguagem: as expressões-chaves, as ideias centrais e a ancoragem. As expressões-chaves $(\mathrm{ECH})$ são extratos literais das falas dos professores que revelam a essência do discurso. As ideias centrais (IC) descrevem o "sentido de cada um dos discursos analisados e de cada conjunto homogêneo de $\mathrm{ECH}$, que vai dar nascimento, posteriormente ao DSC" (LEFÈVRE, LEFÈVRE, 2005, p. 17). A ancoragem (AC) "é uma manifestação linguística explícita de uma dada teoria, ou ideologia, ou crença que o autor do discurso professa e que, na qualidade de afirmação genérica, está sendo usada pelo enunciador para ‘enquadrar’ uma situação específica” (LEFÈVRE, LEFÈVRE, 2005, p. 17).

Para produzir um DSC primeiramente realiza-se uma análise do material produzido e extrai de cada declaração, as ECH e suas correspondentes IC ou AC. É a partir do conjunto dessas três figuras de linguagens de sentido igual ou semelhante que se produz o discurso que resume a fala do coletivo, ressalta-se que o DSC é escrito na primeira pessoa do singular, pois de acordo com Lefèvre e Lefèvre (2005)

O sujeito coletivo se expressa, então, através de um discurso emitido no que se poderia chamar de primeira pessoa (coletiva) do singular. Trata-se de um eu sintático que, ao mesmo tempo em que sinaliza a presença de um sujeito individual do discurso, expressa uma referência coletiva na medida em que esse eu fala pela ou em nome de uma coletividade. Esse discurso coletivo expressa um sujeito coletivo, que viabiliza um pensamento social: como afirma Gertz, a sociedade ou as culturas podem ser lidas como um texto. (LEFÈVRE; LEFÈVRE, 2005, p. 16).

O Instrumento de Análise do Discurso (IAD) é composto pelas expressões chaves, ideias centrais e ancoragem e tem como finalidade organizar os extratos dos depoimentos dos docentes, auxiliando no entendimento da construção dos discursos (DUARTE; MAMEDE; ANDRADE, 2009). Primeiramente, agrupou-se integralmente as respostas dos docentes na primeira coluna, e destacou-se com cores diferentes os extratos mais significativos, que são as ECH. Na segunda coluna colocou-se as IC correspondentes as ECH e na terceira coluna AC (Quadro 1). 
RELACult - Revista Latino-Americana de Estudos em Cultura e Sociedade

Revista Latinoamericana de Estudios en Cultura y Sociedad | Latin American Journal of Studies in Culture and Society

V. 05, ed. especial, abr., 2019, artigo n 1232 | claec.org/relacult |e-ISSN: 2525-7870

Quadro 1 - Extrato do Instrumento de Análise do Discurso 1

\begin{tabular}{|c|c|c|}
\hline ECH & IC & $\mathbf{A C}$ \\
\hline $\begin{array}{l}\text { Diria que é uma profissão gratificante, com o devido esforço e com as } \\
\text { devidas oportunidades é possível se ganhar bem, sendo professor, apesar } \\
\text { do que muitas pessoas especulam. O reconhecimento de um bom } \\
\text { profissional sempre vem, por parte dos alunos, da instituição e da } \\
\text { comunidade. Ser professor não é fácil, mas nenhuma profissão é, o } \\
\text { importante é fazermos o que nos dá prazer e buscar sempre por uma } \\
\text { qualificação, tanto para melhorar a prática como para se manter no } \\
\text { mercado de trabalho. }\end{array}$ & $\begin{array}{l}\text { Motivação } \\
\text { Reconhecimento } \\
\text { Dificuldades } \\
\text { Formação continuada }\end{array}$ & $\begin{array}{l}\text { BEM-ESTAR } \\
\text { VALORIZAÇÃO } \\
\text { PROFISSIONAL } \\
\text { INFRAESTRUTURA } \\
\text { FORMAÇÃO }\end{array}$ \\
\hline $\begin{array}{l}\text { Que tenha coragem e força para encontrar uma geração que não quer } \\
\text { aprender, que é dependente ao extremo e direções de escola que importam- } \\
\text { se mais com índices positivos do que com o aprendizado real dos alunos }\end{array}$ & Realidade Es & INFRAESTRUTURA \\
\hline $\begin{array}{l}\text { Não somos valorizados, apesar de ser a única profissão capaz de formar } \\
\text { todas as outras. }\end{array}$ & & $\begin{array}{l}\text { VALORIZAÇÃO } \\
\text { PROFISSIONAL }\end{array}$ \\
\hline $\begin{array}{l}\text { Diria que a escolha é sempre dele mas que no meu caso, eu adoro o que } \\
\text { faço e me sinto realizada. É como se a matemática e o estar dentro de uma } \\
\text { escola fosse algo tão significativo e importante para mim, como a vida. } \\
\text { Quando se nota a prática elaborada, fruto de um planejamento, se } \\
\text { concretizar, olhar nos olhos de um estudante e perceber seu entusiasmo, é } \\
\text { muito gratificante. }\end{array}$ & Motivação & BEM-ESTAR \\
\hline
\end{tabular}

Fonte: Os Autores

Posteriormente foi selecionada as ECH que continham AC semelhantes e se construiu um fragmento de DSC que expressa as opiniões dos docentes pesquisados, ressalta-se que só foram utilizadas as AC Bem-estar e Formação neste exemplo. Quando necessário, são utilizados conectores para darem coerência ao discurso, cabe salientar que quando utilizados, eles são sublinhados, como fica explícito no Quadro 2.

Quadro 2 - Extrato do Instrumento de Análise do Discurso 2

\begin{tabular}{|c|c|}
\hline ECH & \\
\hline $\begin{array}{l}\text { é gratificante, com o devido esforço e com as devidas } \\
\text { oportunidades é possível se ganhar bem } \\
\text { buscar por uma qualificação, tanto para melhorar a prática como } \\
\text { para se manter no mercado de trabalho. } \\
\text { eu adoro o que faço e me sinto realizada. } \\
\text { Tenha amor pela profissão } \\
\text { ensinar matemática é abrir caminhos para o viver } \\
\text { O ensino da matemática através de uma metodologia adequada } \\
\text { termina com o pré-conceito de uma disciplina difícil de } \\
\text { compreender } \\
\text { Que o curso superior em especial o curso de licenciatura da FURG, }\end{array}$ & $\begin{array}{l}\text { conversa, esquecer tudo e rea } \\
\text { entender que por mais que } \\
\text { estudos, você provavelmente } \\
\text { do iceberg. O curso superio } \\
\text { licenciatura da FURG, nã } \\
\text { profissão. Quando assumimo } \\
\text { consciência que é uma profis }\end{array}$ \\
\hline
\end{tabular}


Se não existir amor no que fazemos nem adianta começar, pois sem afeto as tarefas tornam-se um fardo pesado demais para ser carregado e as relações tornam-se frias e superficiais. quando assumimos à docência temos de ter consciência que é uma profissão na qual lidamos com o outro e isso não tem valor através dela que podemos transformar pessoas. a possibilidade de fazer a diferença na vida dos educandos ter o dom, gostar, amar a sua profissão!

a profissão não pode ser uma obrigação a cumprir, mas deve sentir prazer ao cumpri-la

veja a beleza naqueles que percebem teu empenho e valoriza o teu trabalho

Não deixe de cuidar de si em detrimento do trabalho, pois sem saúde e equilíbrio, o maior prejudicado será você, mas, indiretamente, isso refletirá no futuro de seus alunos. A Educação é uma montanha-russa e a Matemática, acredito eu, seja aquela que mais loopings deve superar.

é muito reconfortante quando um aluno, quase sempre depois de deixar o ensino médio, nos reencontra ou manda alguma mensagem agradecendo se doar faz parte da profissão docente. tenha amor pela profissão, pois se não existir amor no que fazemos nem adianta começar, pois sem afeto as tarefas tornam-se um fardo pesado demais para ser carregado e as relações tornam-se frias e superficiais, veja a beleza naqueles que percebem teu empenho e valoriza o teu trabalho é um sentimento bem estranho de completude quando perceberes que fizestes, nem que seja mínima, diferença na vida dos seus alunos. O ensino da matemática através de uma metodologia adequada termina com o pré-conceito de uma disciplina difícil de compreender. Mas não deixe de cuidar de si em detrimento do trabalho, pois sem saúde e equilíbrio, o maior prejudicado será você, mas, indiretamente, isso refletirá no futuro de seus alunos. A Educação é uma montanha-russa e a Matemática, acredito eu, seja aquela que mais loopings deve superar, e nunca pare de aprender, buscar uma qualificação, tanto para melhorar a prática como para se manter no mercado de trabalho.

O discurso do Quadro 2 foi produzido através das ECH de acordo com suas AC, as $\mathrm{ECH}$ foram ordenadas e conectadas para transformar o discurso em um texto coeso e coerente. Os Quadros 1 e 2 ilustraram como foram realizadas essas etapas de construção do DSC nesse trabalho. Cabe ressaltar que até o momento, com a leitura de 30 relatos, surgiram quatro AC: Bem-estar, Valorização Profissional, Infraestrutura e Formação. Porém, para a produção desse discurso utilizaram-se apenas as AC Bem-estar e Formação, como fica evidenciado na análise do DSC na próxima seção.

\section{Análise do Discurso do Sujeito Coletivo}

Até o momento foram analisados 30 relatos da questão aberta: "O que você diria a um jovem que está fazendo a escolha pela licenciatura em matemática? Registre teus sentimentos e percepções a partir do que tens vivenciado na tua prática”. Salienta-se que este discurso foi construído somente com as ancoragens: bem-estar e formação, ou seja, duas das quatro ancoragens que surgiram da análise desses 30 primeiros relatos.

Quadro 3 - DSC: Motivações dos Professores

Fazer licenciatura em Matemática é, para começo de conversa, esquecer tudo e reaprender tudo novamente. É entender que por mais que se considere um ás nos estudos, você provavelmente apenas considerou a ponta do iceberg. O curso superior em especial o curso de licenciatura da FURG, não retrata a realidade da profissão. Quando assumimos à docência temos de ter consciência que é uma profissão na qual lidamos com o outro e isso não tem valor, ensinar matemática é abrir caminhos para o viver, pois temos a oportunidade de partilhar vivencias, de nos reinventar a cada ano. Que partilhamos o lado bom da vida que é o processo de construção. Que a profissão tem seus encantos, sua magia. Verás uma satisfação crescente em você toda vez que um aluno compreender um conceito, definição que não tinha ideia da onde tinha surgido. Se alegrará cada vez que um aluno transcender de suas dificuldades e começar a reconhecer seu potencial. É muito reconfortante quando um aluno, quase sempre depois de deixar o ensino médio, nos reencontra ou manda alguma mensagem agradecendo. A 
profissão não pode ser uma obrigação a cumprir, mas deve sentir prazer ao cumpri-la, ter o dom, gostar, amar a sua profissão, eu adoro o que faço e me sinto realizada. Se doar faz parte da profissão docente, é gratificante, com o devido esforço e com as devidas oportunidades é possível se ganhar bem. Então tenha amor pela profissão, pois se não existir amor no que fazemos nem adianta começar, pois sem afeto as tarefas tornam-se um fardo pesado demais para ser carregado e as relações tornam-se frias e superficiais, veja a beleza naqueles que percebem teu empenho e valoriza o teu trabalho é um sentimento bem estranho de completude quando perceberes que fizestes, nem que seja mínima, diferença na vida dos seus alunos. $\mathrm{O}$ ensino da matemática através de uma metodologia adequada termina com o pré-conceito de uma disciplina difícil de compreender. Mas, não deixe de cuidar de si em detrimento do trabalho, pois sem saúde e equilíbrio, o maior prejudicado será você, mas, indiretamente, isso refletirá no futuro de seus alunos. A Educação é uma montanha-russa e a Matemática, acredito eu, seja aquela que mais loopings deve superar, e nunca pare de aprender, buscar uma qualificação, tanto para melhorar a prática como para se manter no mercado de trabalho.

Fonte: Os Autores

Este primeiro DSC traz as motivações que os professores têm e sentem ao lecionar. Para a discussão dessa seção, serão selecionados alguns extratos das falas dos professores no DSC e de autores que corroborem com o assunto. O primeiro extrato selecionado desse DSC se refere a formação inicial dos professores em matemática.

Fazer licenciatura em Matemática é, para começo de conversa, esquecer tudo e reaprender tudo novamente. É entender que por mais que se considere um ás nos estudos, você provavelmente apenas considerou a ponta do iceberg. $\mathrm{O}$ curso superior em especial o curso de licenciatura da FURG, não retrata a realidade da profissão. (DSC: Motivações dos Professores)

De acordo com Pereira, Carvalho e Castro Filho (2016), em uma pesquisa feita com graduandos do curso de Licenciatura Integrada em Matemática e Física observou-se que as maiores dificuldades enfrentadas pelos alunos é a falta de base dos conteúdos ministrados e o excesso de conteúdos por semestre. Desta forma, constata-se que muitas vezes a carga horária dos cursos de licenciatura tem diversas disciplinas voltadas para a área das exatas e poucas voltadas para a área da prática docente, com isso, tem-se uma formação fortemente centrada nos conceitos, o que não necessariamente significa formar um professor de matemática. Nesse sentido, Corrêa e Schnetzler (2011) afirmam que os licenciados ao ingressarem na docência sentem dificuldades devido ao distanciamento da realidade exposta durante a graduação e a encontrada no ambiente escolar, pois não existe nem escola, nem aluno ideal, pois o perfil de alguns alunos hoje envolvem baixo conhecimento, falta de motivação, responsabilidade e interesse.

Foram destacados também, extratos que se referem aos sentimentos de prazer e satisfação em relação à prática docente, em ver a beleza de ensinar e de ser um agente transformador na vida dos alunos.

ensinar matemática é abrir caminhos para o viver, pois temos a oportunidade de partilhar vivencias, de nos reinventar a cada ano. Que partilhamos o lado bom da 
vida que é o processo de construção. [...] A profissão não pode ser uma obrigação a cumprir, mas deve sentir prazer ao cumpri-la, ter o dom, gostar, amar a sua profissão, eu adoro o que faço e me sinto realizada. Se doar faz parte da profissão docente, é gratificante, [...] Então tenha amor pela profissão, pois se não existir amor no que fazemos nem adianta começar, pois sem afeto as tarefas tornam-se um fardo pesado demais para ser carregado e as relações tornam-se frias e superficiais (DSC: Motivações dos Professores)

Nesse trecho fica evidente que embora a profissão docente enfrente diversas dificuldades, ela também transmite sentimentos positivos e de satisfação ao professor. De acordo com Larocca e Girardi (2011) a satisfação e a motivação são condições indispensáveis, não somente para o bem-estar do docente, mas para a qualidade do seu trabalho. Alves (2016) complementa que amar as crianças e amar a profissão é o mais importante motivador de outras condutas profissionais como, estar aberto a mudanças, ter compromisso, dedicação e responsabilidade, e buscar aperfeiçoamento. Salienta também que o amor e o prazer "no trabalho são identificados como a principal e indispensável motivação para a busca de aprimoramento profissional, subordinando até mesmo a busca de formação e profissionalização" (ALVES, 2016, p. 7).

Um professor que se intitula feliz com sua escolha pela docência e expressa sentimentos de prazer em lecionar, tem chances reduzidas de desenvolver mal-estar. Pois, um professor motivado, realizado, e que sente bem-estar na profissão, tem uma maior capacidade de conseguir superar os obstáculos da docência, desenvolvendo uma maior resiliência e estratégias de coping $^{4}$ (LETTNIN et al, 2013).

No próximo extrato destacado, os professores relatam que através da implementação de uma metodologia adequada é possível mudar o estigma de que a matemática é um conteúdo difícil de compreender.

O ensino da matemática através de uma metodologia adequada termina com o préconceito de uma disciplina difícil de compreender. (DSC: Motivações dos Professores)

Silveira (2002) afirma que embora a matemática seja uma disciplina que reprove um número significativo de alunos, a comunidade escolar não contesta essas reprovações, pois acredita-se que a matemática é difícil, que ela é para poucos entenderem. Desta forma, é importante que os professores busquem práticas diferenciadas em suas aulas de modo que

\footnotetext{
4 "O termo coping pode ter o significado de lidar com, enfrentar, encarar, ultrapassar, fazer face, dar resposta a, reagir a ou adaptar-se a circunstâncias adversas" (POCINHO, CAPELO, 2009, p.354).
} 
incentivem e mostrem aos alunos que a matemática é uma ciência bela e que através de contextualizações é possível entender e atribuir significado.

Porém tem-se clareza que na realidade educacional em que os professores muitas vezes vivenciam é complicado conseguir elaborar aulas contextualizadas, uma vez que, eles necessitam de tempo e, em alguns casos, de formação continuada para construir esse tipo de aula, mais atrativa. Em consequência, muitos dos professores que tentam fazer um trabalho realmente de qualidade acabam se sobrecarregando e utilizando as horas de descanso para a realização de tarefas escolares. Cabe salientar que, embora seja importante o professor se dedicar ao trabalho, ele não pode abdicar de sua saúde e qualidade de vida, pois quando o professor não se sente bem ele sofre e, com isso, seus alunos também, uma vez que os sentimentos dos docentes refletem em sua prática profissional, como é evidenciado no fragmento do DSC abaixo.

Mas, não deixe de cuidar de si em detrimento do trabalho, pois sem saúde e equilíbrio, o maior prejudicado será você, mas, indiretamente, isso refletirá no futuro de seus alunos. (DSC: Motivações dos Professores)

Logo, entende-se que para se ter uma educação com qualidade é necessário que os docentes estejam bem em todos os aspectos, tanto fisicamente, quanto emocionalmente. Em concordância Romão (2007) afirma que um professor "não consegue ajudar quem quer que seja a se auto-educar, se não demonstra ser uma pessoa educada, ou seja, equilibrada, estável, capaz de amar, capaz de amar a si mesma". (ROMÃO, 2007, p. 17), o autor ainda complementa ao afirmar que "um educador massacrado pelo mal-estar docente jamais conseguirá fazer bem a quem quer que seja, porque não está bem consigo mesmo" (ROMÃO, 2007, p. 17).

Também foi destacado nesse DSC a importância da formação continuada, uma vez que é sempre necessário estar se qualificando, pois isso permite ao professor ter maiores condições de lidar com as dificuldades ligadas a sua prática profissional.

A Educação é uma montanha-russa e a Matemática, acredito eu, seja aquela que mais loopings deve superar, e nunca pare de aprender, buscar uma qualificação, tanto para melhorar a prática como para se manter no mercado de trabalho. (DSC: Motivações dos Professores)

De acordo com Miceli (2017) a formação continuada torna os professores mais capacitados sobre os aspectos pedagógicos, além de os incentivar a descobrir outras estratégias para as dificuldades encontradas no dia a dia, e com isso, tentar realizar mudanças 
na comunidade escolar. Uma vez que a formação continuada oferece ao docente a oportunidade de refletir e repensar sua prática profissional, além de possibilitar a descoberta de novos saberes.

\section{Apreensões dos discursos vislumbrando possibilidades}

Através dos dados enunciados nessa pesquisa, é possível constatar a importância da satisfação e motivação dos professores pela docência, pois com esses sentimentos o trabalho é realizado com mais prazer e bem-estar, uma vez que, os professores que são felizes pela sua escolha e prática profissional têm menos chances de desenvolver sintomas de mal-estar, pois sentem prazer em estar na presença dos alunos e em lecionar.

Ressalta-se que embora entenda-se que a educação apresente dificuldades em seus índices de desempenho, e que a profissão docente enfrente dificuldades em repensar suas práticas apresentando alternativas, acredita-se que o caminho para sair dessa situação é possibilitar uma formação inicial de maior qualidade para ingressar no mercado de trabalho. Ou seja, formações que tratem dos conteúdos específicos dos cursos, mas que abordem com ênfase a parte pedagógica, para preparar os licenciandos para lecionar na realidade da educação básica.

Porém, também é necessário investir em buscar formações continuadas, de modo que os professores não estagnem, mas estejam sempre buscando novos conhecimentos, novos métodos de ensinar e de deixar as aulas mais atraentes através de metodologias adequadas que, por exemplo, desmistifiquem a matemática como uma disciplina difícil e mudem o cenário atual em que e essa disciplina é a responsável pelo maior número de retenção de alunos nas escolas de educação básica.

É importante que os professores se dediquem a desempenhar seu papel de educador da melhor forma possível, sempre buscando métodos de inovar e cativar a atenção dos alunos em sala de aula, porém esse docente não deve extrapolar sua carga horária de trabalho com planejamentos, pois ele necessita de tempo para descansar e tempo para cuidar de si, pois a docência é apenas parte da vida de um professor.

Este trabalho permite observar que, embora haja uma desvalorização social e econômica do professor, que afeta seu desempenho em sala de aula, é possível que a profissão também traga momentos de satisfação. Uma vez que as atividades que o sujeito esteja desempenhando lhe sejam prazerosas, isso lhe permite experimentar sentimentos positivos quanto à docência, prevenindo o seu adoecimento. Porém, acreditamos que seja interessante observar em futuros estudos o quanto que o docente acaba aceitando esta desvalorização 
social e não identificando como algo danoso tanto para si, quanto para o seu desempenho profissional, os aspectos negativos da docência, como por exemplo as deficitárias infraestruturas das escolas e a necessidade de uma extenuante jornada de trabalho para que possa ter um retorno financeiro minimamente adequado.

\section{Referências}

ALVES, N. N. L. "Amor à profissão, dedicação e o resto se aprende": significados da docência em educação infantil na ambiguidade entre a vocação e a profissionalização. In: 29a Reunião Anual da ANPED, 2016, Rio de Janeiro. p. 1 - 17. Disponível em: http://www.anped.org.br/sites/default/files/gt07-2570.pdf. Acesso em: 07 jun. 2018.

BARREIROS, J. L. Fatores que influenciam na motivação de professores. 2008. 105 f. TCC (Graduação) - Curso de Psicologia, Centro Universitário de Brasília, Brasília, 2008. Disponível em: http://repositorio.uniceub.br/bitstream/123456789/2581/2/20312042.pdf23. Acesso em: 23 jun. 2017.

CARDOSO, C. G. L. V.; COSTA, N. M. S. C. Fatores de satisfação e insatisfação profissional de docentes de nutrição. Ciência \& Saúde Coletiva, Rio de Janeiro, v. 21, n. 8, p.2357-2364, 2016. Disponível em: http://www.scielo.br/pdf/csc/v21n8/1413-8123-csc-2108-2357.pdf. Acesso em: 01 dez. 2017.

CORRÊA, T. H. B.; SCHNETZLER, R. P. O Início na Carreira Docente: Dificuldades de Professores de Química no Ensino Médio. In: VIII Centro Nacional de Pesquisa em Educação em Ciências; I Congresso Iberoamericano de Pesquisa em Ensino das Ciências de Campinas, 2011, Campinas. $\quad$ p. $\quad 1 \quad$ - $\quad 9 . \quad$ Disponível em: http://api.ning.com/files/4VVOgLw2s7VMdOjcUv*sS5ytGu62W-

0621bfEK47WXJau4ZMlnDer8vzEr7KgBFXFeadr7cU0RYrM6qaTVceQX5N1W8nmqii/ini cionacarreira.enpec.pdf. Acesso em: 28 maio 2018.

DUARTE, S. J. H.; MAMEDE, M. V.; ANDRADE, S. M. O. de. Opções Teórico Metodológicas em Pesquisas Qualitativas: Representações Sociais e Discurso do Sujeito Coletivo. Revista Saúde e Sociedade - USP. São Paulo, v. 18, n. 4, p. 620626, 2009. Disponível em: http://www.scielo.br/pdf/sausoc/v18n4/06.pdf. Acesso em: 15 jan. 2017.

LAROCCA, P.; GIRARDI, P. G. Trabalho, satisfação e motivação docente: um estudo exploratório com professores da educação básica. In: X Congresso Nacional de Educação (EDUCERE), 2011, Curitiba. p. 1932 - 1948. Disponível em: http://educere.bruc.com.br/CD2011/pdf/5429_2605.pdf. Acesso em: 28 maio 2018.

LEFÈVRE, F.; LEFÈVRE, A. M. C. O discurso do Sujeito Coletivo: Um novo enfoque em pesquisa qualitativa (Desdobramentos). 2. ed. Caxias do Sul: EDUCS, 2005. 256 p.

LETTNIN, C. et al. Resiliência e educação: aportes teórico-práticos para a docência. Revista Contrapontos - Eletrônica, Itajaí, v. 14, n. 2, p.322-338, maio/ago. 2013. Disponível em: https://siaiap32.univali.br/seer/index.php/rc/article/view/4756/3270. Acesso em: 03 dez. 2017. 
LIPP, M. N. O estresse do professor. $7^{\text {a }}$ ed. Campinas, SP: Papirus, 2012.

MELLO, G. N. Formação inicial de professores para a educação básica: uma (re)visão radical. São Paulo em Perspectiva, São Paulo, v. 1, n. 14, p.98-110, 2000. Disponível em: http://www.scielo.br/pdf/spp/v14n1/9807.pdf. Acesso em: 08 out. 2018.

MICELI, M. Z. D. A importância da Formação Continuada de professores. 2017. Disponível em: http://educacao.estadao.com.br/blogs/blog-dos-colegios-santa-amalia/a-importancia-daformacao-continuada-de-professores/. Acesso em: 28 maio 2018.

PEREIRA, 1. R. B.; CARVALHO, h. C.; CASTRO FILHO, t. J. Dificuldades enfrentadas pelos futuros professores no curso de licenciatura integrada em matemática e física na UFOPA. In: Encontro Nacional de Educação Matemática, XII., 2016, São Paulo. p. 1 - 10. Disponível em: http://www.sbem.com.br/enem2016/anais/pdf/4809_3526_ID.pdf. Acesso em: 28 maio 2018.

POCINHO, M.; CAPELO, M. R. Vulnerabilidade ao stress, estratégias de coping e autoeficácia em professores portugueses. Educação e Pesquisa, São Paulo, v. 35, n. 2, p.351367, maio/ago. 2009. Disponível em: http://www.scielo.br/pdf/ep/v35n2/a09v35n2.pdf. Acesso em: 11 jun. 2018.

ROMÃO, J. E. Docente: um ser humano acima de tudo. Visão Global, v. 10, n. 1, p. 7-22, jan./jun. 2007.

SILVEIRA, M. R. A. "Matemática é dificil": um sentido pré-construído evidenciado na fala dos alunos, $2002 . \quad$ Disponível em:http://www.ufrrj.br/emanped/paginas/conteudo_producoes/docs_25/matematica.pdf.

Acesso em: 7 mai. 2017.

SOUTO, R. M. A. O abandono do magistério entre os profissionais egressos da licenciatura em matemática da UFSJ - indícios sobre a condição docente no Brasil. In: Congresso Iberoamericano de Educação Matemática, VII., 2013, Montevidéu. Actas del VII CIBEM. 2013. p. 4555 - 4562. Disponível em: http://cibem7.semur.edu.uy/7/actas/pdfs/257.pdf. Acesso em: 08 out. 2018.

TARDIF, M. Saberes docentes e formação profissional. 2. ed. Petrópolis, RJ: Vozes, 2002. 